\title{
Exogenous melatonin improves salt stress adaptation of cotton seedlings by regulating active oxygen metabolism
}

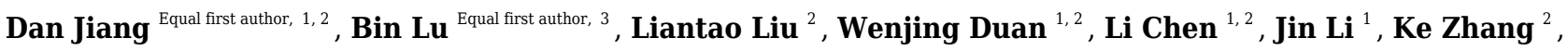

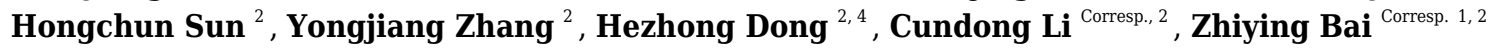 \\ ${ }^{1}$ State Key Laboratory of North China Crop Improvement and Regulation / College of Life Science, Hebei Agricultural University, Baoding, China \\ 2 State Key Laboratory of North China Crop Improvement and Regulation / Key Laboratory of Crop Growth regulation of Hebei Province / College of \\ Agronomy, Hebei Agricultural University, Baoding, China \\ 3 College of Landscape and Tourism, Hebei Agricultrual University, Baoding, China \\ 4 Cotton Research Center/Key Laboratory of Cotton Breeding and Cultivation in Huang-huai-hai Plain, Ministry of Agriculture, Shandong Academy of \\ Agricultural Sciences, Jinan, China
}

Corresponding Authors: Cundong Li, Zhiying Bai

Email address: nxylcd@hebau.edu.cn, zhiyingbai@126.com

Melatonin is a small-molecule indole hormone that plays an important role in participating in biotic and abiotic stress resistance. Melatonin has been confirmed to promote the normal development of plants under adversity stress by mediating physiological regulation mechanisms. However, the mechanisms by which exogenous melatonin mediates salt tolerance via regulation of antioxidant activity and osmosis in cotton seedlings remain largely unknown. In this study, the regulatory effects of melatonin on reactive oxygen species (ROS), the antioxidant system, and osmotic modulators of cotton seedlings were determined under 0-500 $\mu \mathrm{M}$ melatonin treatments with salt stress induced by $150 \mathrm{mM}$ $\mathrm{NaCl}$ treatment. Cotton seedlings under salt stress exhibited an inhibition of growth, excessive hydrogen peroxide $\left(\mathrm{H}_{2} \mathrm{O}_{2}\right)$, superoxide anion $\left(\mathrm{O}_{2}^{-}\right)$, and malondialdehyde (MDA) accumulations in leaves, increased activity levels of superoxide dismutase (SOD), peroxidase (POD), catalase (CAT), and ascorbate peroxidase (APX), and elevated ascorbic acid (AsA) and glutathione (GSH) content in leaves. However, the content of osmotic regulators (i.e., soluble sugars and proteins) in leaves was reduced under salt stress. This indicates high levels of ROS were produced, and the cell membrane was damaged. Additionally, osmotic regulatory substance content was reduced, resulting in osmotic stress, which seriously affected cotton seedling growth under salt stress. However, exogenous melatonin at different concentrations reduced the contents of $\mathrm{H}_{2} \mathrm{O}_{2}, \mathrm{O}_{2}$, and MDA in cotton leaves, increased the activity of antioxidant enzymes and the content of reductive substances (i.e., AsA and GSH), and promoted the accumulation of osmotic regulatory substances in leaves under salt stress. These results suggest that melatonin can inhibit ROS production in cotton seedlings, improve the activity of the antioxidant 
enzyme system, raise the content of osmotic regulation substances, reduce the level of membrane lipid peroxidation, and protect the integrity of the lipid membrane under salt stress, which reduces damage caused by salt stress to seedlings and effectively enhances inhibition of salt stress on cotton seedling growth. These results indicate that $200 \mu \mathrm{M}$ melatonin treatment has the best effect on the growth and salt tolerance of cotton seedlings. 
1 Exogenous melatonin improves salt stress adaptation

2 of cotton seedlings by regulating active oxygen

3 metabolism

4 Dan Jiang ${ }^{1,2, f}$, Bin Lu ${ }^{3, f}$, Liantao Liu ${ }^{2}$, Wenjing Duan ${ }^{1,2}$, Li Chen ${ }^{1,2}$, Jin Li ${ }^{1}$, Ke Zhang ${ }^{2}$

5 Hongchun Sun ${ }^{2}$, Yongjiang Zhang ${ }^{2}$, Hezhong Dong ${ }^{2,4}$, Cundong Li ${ }^{2 *}$, Zhiying Bai 1,2*

$6 \quad{ }^{1}$ State Key Laboratory of North China Crop Improvement and Regulation / College of Life

7 Science, Hebei Agricultural University, Baoding, 071001, Hebei, China

$8 \quad{ }^{2}$ State Key Laboratory of North China Crop Improvement and Regulation / Key Laboratory of

9 Crop Growth regulation of Hebei Province / College of Agronomy, Hebei Agricultural

10 University, Baoding, 071001, Hebei, China

$11{ }^{3}$ College of Landscape and Tourism, Hebei Agricultural University, Baoding, 071001, China

$12{ }^{4}$ Cotton Research Center/Key Laboratory of Cotton Breeding and Cultivation in Huang-huai-hai

13 Plain, Ministry of Agriculture, Shandong Academy of Agricultural Sciences, Jinan 250100,

14 Shandong, China

$15{ }^{\mathrm{f}}$ These authors equally contributed to this research work and should be considered co-first

16 authors

17 Corresponding Author:

18 Zhiying Bai

19 Cundong Li

20 NO. 289 Linyusi Street, Baoding, Hebei Province, 071000, China

21 Email address: zhiyingbai@126.com

nxylcd@hebau.edu.cn

\section{Abstract}

24 Melatonin is a small-molecule indole hormone that plays an important role in participating in

25 biotic and abiotic stress resistance. Melatonin has been confirmed to promote the normal

26 development of plants under adversity stress by mediating physiological regulation mechanisms.

27 However, the mechanisms by which exogenous melatonin mediates salt tolerance via regulation

28 of antioxidant activity and osmosis in cotton seedlings remain largely unknown. In this study, the

29 regulatory effects of melatonin on reactive oxygen species (ROS), the antioxidant system, and 
osmotic modulators of cotton seedlings were determined under 0-500 $\mu \mathrm{M}$ melatonin treatments with salt stress induced by $150 \mathrm{mM} \mathrm{NaCl}$ treatment. Cotton seedlings under salt stress exhibited an inhibition of growth, excessive hydrogen peroxide $\left(\mathrm{H}_{2} \mathrm{O}_{2}\right)$, superoxide anion $\left(\mathrm{O}_{2}{ }^{-}\right)$, and malondialdehyde (MDA) accumulations in leaves, increased activity levels of superoxide dismutase (SOD), peroxidase (POD), catalase (CAT), and ascorbate peroxidase (APX), and elevated ascorbic acid (AsA) and glutathione (GSH) content in leaves. However, the content of osmotic regulators (i.e., soluble sugars and proteins) in leaves was reduced under salt stress. This indicates high levels of ROS were produced, and the cell membrane was damaged. Additionally, osmotic regulatory substance content was reduced, resulting in osmotic stress, which seriously affected cotton seedling growth under salt stress. However, exogenous melatonin at different concentrations reduced the contents of $\mathrm{H}_{2} \mathrm{O}_{2}, \mathrm{O}_{2}{ }^{-}$, and MDA in cotton leaves, increased the activity of antioxidant enzymes and the content of reductive substances (i.e., AsA and GSH), and promoted the accumulation of osmotic regulatory substances in leaves under salt stress. These results suggest that melatonin can inhibit ROS production in cotton seedlings, improve the activity of the antioxidant enzyme system, raise the content of osmotic regulation substances, reduce the level of membrane lipid peroxidation, and protect the integrity of the lipid membrane under salt stress, which reduces damage caused by salt stress to seedlings and effectively enhances inhibition of salt stress on cotton seedling growth. These results indicate that $200 \mu \mathrm{M}$ melatonin treatment has the best effect on the growth and salt tolerance of cotton seedlings.

\section{Subjects Agricultural Science Plant Science}

Keywords Cotton, Melatonin, Salt stress, ROS, Antioxidant systems, Osmotic substance Introduction

As the ecological environment continues to change at a global scale, the area of the world's saline-alkali land has increased annually, and soil salinization has thus become a major impediment to agricultural development (Munns, 2002). Salt stress brings ionic stress and secondary stresses such as osmotic stress and oxidative stress to plants, which interfere with the normal development of plants. When plants are subjected to salt stress, their physiological and biochemical reactions cannot proceed normally, leading to reduced yields and quality and even plant death (Parida and Das, 2005; Liang et al., 2018). Cotton is the field crop with the longest planting industry chain in the world, and it plays an important role in national economies (Luo et al., 2018). The seedling stage is a fragile and critical stage in the growth and development of 
61 cotton, which is severely affected by salt stress, so the exploration of the growth and regulation

62 of cotton seedlings under salt stress is of great importance.

63 Melatonin ( $N$-acetyl-5-methoxytryptophan, MT) plays an important role in promoting plant

64 development and responses to abiotic stress (Ren et al., 2019). Melatonin was first isolated from

65 the pineal gland of cattle and was subsequently discovered in vascular plants in 1995 (Dubbels et

66 al., 1995; Hattori et al., 1995). The $N$-acetyl and 5-methoxy functional groups in the structure of

67 melatonin not only establish its high lipophilicity and hydrophilicity, but also determine the

68 specificity of its binding to receptors (Arnao and Hernández-Ruiz, 2015). Isotopic tracing

69 experiments have confirmed that melatonin is synthesized in plants (Murch et al., 2000), and it is

70 believed that mitochondria and chloroplasts in plants are the synthesis sites of melatonin, and in

71 most organisms, melatonin can be transferred from mitochondria and chloroplasts to other

72 tissues and organs (Tan et al., 2013). Subsequent studies have shown that melatonin is widely

73 present in almost all plant species, and people have also found melatonin in various organs of

74 higher plants (Kolar et al., 2005; Okazaki et al., 2009; Saeteaw et al., 2013), at concentrations

75 ranging from $0.1 \mathrm{pg} \cdot \mathrm{g}^{-1}(\mathrm{FW})$ to $20 \sim 30 \mu \mathrm{g} \cdot \mathrm{g}^{-1}$ (FW) (Hardeland, 2016) and even $230 \mu \mathrm{g} \cdot \mathrm{g}^{-1}$

76 (DW) (Oladi et al., 2014). The biosynthetic precursor of melatonin is tryptophan, which has a

77 function similar to that of auxin (Arnao and Hernández-Ruiz, 2018). Subsequent studies have

78 shown that melatonin plays an important role in the regulation of seed germination (Tiryaki et

79 al., 2012), plant growth (Manchester et al., 2015), cell division (Park et al., 2012), delaying leaf

80 senescence (Byeon et al., 2012; Wang et al., 2013), and defense against abiotic stresses such as

81 extreme temperature (Golam et al., 2019), heavy metals (Kaya et al., 2019; Posmyk et al., 2008),

82 UV radiation (Afreen et al., 2006), salinity (Zhang et al., 2015), and drought (Sharma et al., 83 2019).

84 As an endogenous free radical scavenger, melatonin not only directly neutralizes reactive 85 oxygen species (ROS) and reactive nitrogen species (RNS), but also stimulates antioxidant 86 enzymes, thereby improving its antioxidant efficiency (Pieri et al., 1994; Reiter et al., 2000).

87 Melatonin has also been shown to scavenge ROS efficiently in vivo using transgenic plants, 88 leading to oxidative stress resistance (Park et al., 2013). Exogenous melatonin increases the 89 activity of superoxide dismutase (SOD; EC 1.15.1.1), peroxidase (POD; EC 1.11.1.7), catalase 90 (CAT; EC 1.11.1.6), and ascorbate peroxidase (APX; EC 1.11.1.11), thus enhancing the 91 antioxidant capacity and reducing the effects of cold and water stress on tea trees (Li et al., 
92 2018a) and cucumber seedlings (Zhang et al., 2013). Ascorbic acid (AsA) and glutathione (GSH)

93 are important reducing substances in plants, where they provide defense against membrane lipid

94 peroxidation. The AsA-GSH cycle system can effectively scavenge free radicals; in apples,

95 melatonin treatment can maintain higher AsA and GSH contents, reduce dehydroascorbic acid

96 (DHA) and oxidized glutathione (GSSG) content, and delay the senescence of leaves in dark

97 conditions (Wang et al., 2012). Plants mainly resist salt stress damage through osmotic

98 regulation (Hu et al., 2018). Studies have shown that soluble sugar and soluble protein are

99 important osmotic regulation substances in increasing the concentration of cell fluid and

100 improving the resistance of plants to salt stress (Park et al., 2016). Melatonin treatment reduces

101 cellular damage by increasing the contents of proline, soluble proteins, and soluble sugars in

102 melon, indicating that exogenous melatonin can enhance the low-temperature adaptability of

103 melon by increasing the content of osmotic substances (Gao et al., 2016).

104 We have previously studied the regulatory effect of exogenous melatonin on cotton seed

105 germination (Xiao et al., 2019; Chen et al., 2020), but the regulation and control of exogenous

106 melatonin on cotton seedlings under salt stress remains unknown. Therefore, in this study, seeds

107 of the cotton cultivar 'Guoxin 9' were employed (1) to examine the effects of different

108 concentrations of exogenous melatonin on osmotic substance content and oxidoreductase activity

109 under salt stress, (2) to explore the mechanism by which exogenous melatonin mitigates

110 impairment of cotton seedling growth under salt stress, and (3) to screen for the optimal

111 melatonin concentration for ameliorating salt stress. This study aims to provide a theoretical

112 basis for the development and utilization of melatonin and the cultivation of salt-resistant cotton.

113 Materials \& Methods

114 Reagents

115 Melatonin ( $N$-acetyl-5-methoxytryptamine) was obtained from Sigma-Aldrich (St. Louis, MO,

116 USA). All other reagents used in all experiments were of analytical grade.

\section{Plant material}

118 A conventional, widely planted transgenic insect-resistant cotton (Gossypium hirsutum L.)

119 cultivar, 'Guoxin No.9,' was used in this study, which was provided by Guoxin Rural Technical

120 Service Association. The experiment was conducted in the greenhouse facilities of Hebei

121 Agricultural University, Baoding City, Hebei Province, China $\left(38.85^{\circ} \mathrm{N}, 115.30^{\circ} \mathrm{E}\right)$ from March

1222019 to April 2020. 


\section{Experimental design}

124 Cotton (Gossypium hirsutum L.) seeds were sterilized with $0.1 \% \mathrm{HgCl}_{2}(w / v)$ for $10 \mathrm{~min}$,

125 followed by three washes with sterile distilled water, to remove any residual disinfectant, and

126 then germinated in an incubator at $25^{\circ} \mathrm{C}$ for $24 \mathrm{~h}$. The germinated seeds were sown in plugs of

127 vermiculite and cultivated in the greenhouse. The seedlings were cultivated at $28 / 25^{\circ} \mathrm{C}$

128 (day/night) with a relative humidity of $45 \pm 5 \%$, and at a photoperiod $\left(600 \mu \mathrm{molm}^{-2} \mathrm{~s}^{-1}\right.$ light

129 intensity) of $16 \mathrm{~h} / 8 \mathrm{~h}$ (day/night). At the two-true-leaf stage, the seedlings were transferred to

130 hydroponic tubes containing $1 / 4$ strength complete nutrient solution for hydroponic culture (in a

131 PVC drum, bottom diameter $110 \mathrm{~cm}$, height $200 \mathrm{~cm}$ ), which was then replaced with half-strength

132 complete nutrient solution for $4 \mathrm{~d}$. Afterwards, seedlings were transferred to full-strength nutrient

133 solution for continued cultivation until the end of the experiment (Wang et al., 2020). The

134 complete nutrient solution for cotton was modified Hoagland solution (Mengel et al., 1983),

135 consisting of $5 \mathrm{mM} \mathrm{KNO}_{3}, 2 \mathrm{mM} \mathrm{MgSO}_{4} \cdot 7 \mathrm{H}_{2} \mathrm{O}, 1 \mathrm{mM} \mathrm{KH}_{2} \mathrm{PO}_{4}, 4.5 \mathrm{mM} \mathrm{NH} \mathrm{H}_{2} \mathrm{PO}_{4}, 5 \mathrm{mM}$

$136 \mathrm{Ca}\left(\mathrm{NO}_{3}\right)_{4} \cdot 4 \mathrm{H}_{2} \mathrm{O}, 0.1 \mathrm{mM}$ EDTA-Na $2,0.1 \mathrm{mM} \mathrm{FeSO}_{4} \cdot 7 \mathrm{H}_{2} \mathrm{O}$, and micronutrients $\left(5 \mu \mathrm{M} \mathrm{H}_{3} \mathrm{BO}_{3}, 7\right.$

$137 \mu \mathrm{M} \mathrm{MnSO}_{4} \cdot \mathrm{H}_{2} \mathrm{O}, 0.8 \mu \mathrm{M} \mathrm{ZnSO}_{4} \cdot 7 \mathrm{H}_{2} \mathrm{O}, 0.3 \mu \mathrm{M} \mathrm{CuSO}_{4} \cdot 5 \mathrm{H}_{2} \mathrm{O}$, and $0.02 \mu \mathrm{M}$

$\left.138\left(\mathrm{NH}_{4}\right)_{6} \mathrm{Mo}_{7} \mathrm{O}_{24} \cdot 4 \mathrm{H}_{2} \mathrm{O}\right)$. Cotton seedlings were fixed into holes with a sponge when transplanted

139 and aerated with a small air pump for $1 \mathrm{~h}$ each day. When the cotton seedlings reached the three-

140 true-leaf stage $6 \mathrm{~d}$ after transplantation, the following treatments were imposed.

141 Seedlings were treated with exogenous MT at various concentrations and subjected to a salt

142 stress treatment; specifically, the cotton seedlings were sprayed respectively with 50, 100, 200,

143 and $500 \mu \mathrm{M}$ MT solutions, until the leaves dripped, once every $24 \mathrm{~h}$ for $12 \mathrm{~d}$. The following

144 experimental groups were arranged into a randomized complete block design with 30 replicates

145 and treated as follows: (1) no melatonin/no salt treatment (control, CK); (2) no melatonin/150

$146 \mathrm{mM} \mathrm{NaCl}$ treatment $(150 \mathrm{mM} \mathrm{NaCl}$, as determined by the pretest screening) (S); (3) $50 \mu \mathrm{M} \mathrm{MT}$ -

147 applied/150 mM NaCl treatment (S+MT50); (4) $100 \mu \mathrm{M}$ MT-applied/150 mM NaCl treatment

148 (S+MT100); (5) $200 \mu \mathrm{M}$ MT-applied/150 mM NaCl treatment (S+MT200); and (6) $500 \mu \mathrm{M}$ MT-

149 applied/150 mM NaCl treatment (S+MT500). Nutrient solutions for each treatment were

150 renewed every $2 \mathrm{~d}$, and 30 PVC hydroponic drums were used for each treatment. The

151 physiological indexes of cotton plants were measured using the third functional leaf (from the

152 top of the plant) at $0,3,6,9$, and $12 \mathrm{~d}$ after treatment.

153 Determination of plant height and leaf area 
154 After treatment, six cotton seedlings were randomly selected at 3, 6, 9, and $12 \mathrm{~d}$ for plant height 155 measurements. At the same time, the green leaf area of the whole plant was calculated using the 156 length and width coefficient method $(0.75)$ based on measurements with a ruler.

157 Determination of ROS and MDA content

158 Hydrogen peroxide $\left(\mathrm{H}_{2} \mathrm{O}_{2}\right)$ content was determined by using a $\mathrm{H}_{2} \mathrm{O}_{2}$ assay kit (A064, Nanjing

159 Jiancheng Bioengineering Institute, Nanjing, China). Superoxide anion $\left(\mathrm{O}_{2}^{-}\right)$production rate was 160 determined by using a $\mathrm{O}_{2}^{-}$assay kit (SA-1-G, Suzhou Comin Biotechnology Co., Ltd., Suzhou, 161 China). To detect lipid peroxidation and membrane integrity, the malondialdehyde (MDA) 162 content was measured by using a MDA assay kit (MDA-1-Y, Suzhou Comin Biotechnology Co., 163 Ltd., Suzhou, China) according to the manufacturer's instructions.

164 Determination of antioxidant enzyme activity

165 Superoxide dismutase (SOD), peroxidase (POD), catalase (CAT), and ascorbate peroxidase 166 (APX) activity levels were determined by using assay kits for each respective enzyme (SOD-1167 Y, POD-1-Y, CAT-1-W, and APX-1-W, respectively, Suzhou Comin Biotechnology Co., Ltd. 168 Suzhou, China) according to the manufacturer's instructions.

169 Determination of antioxidant metabolites

170 AsA and GSH contents were measured by using AsA and GSH assay kits, respectively (AsA-1-

171 W and GSH-1-W, Suzhou Comin Biotechnology Co., Ltd.) according to the manufacturer's 172 instructions.

\section{Determination of soluble sugar and protein, two osmotic regulators}

174 Soluble sugar content and soluble protein content were determined by using a soluble sugar 175 assay kit (A145-1-1, Nanjing Jiancheng Bioengineering Institute) and a BCA assay kit (BCAP-1176 W, Suzhou Comin Biotechnology Co., Ltd.) according to the manufacturer's instructions.

\section{Statistical analysis}

178 All experimental data were performed using IBM SPSS Statistics 21.0 software and reported as 179 mean \pm standard deviation (SD) values. A statistical significance threshold of $P<0.05$ was used 180 to evaluate one-way ANOVA results.

\section{Results}

182 Exogenous melatonin affects the growth of cotton seedlings under salt stress

183 As can be seen from Fig. 1A, salt stress $(150 \mathrm{mM} \mathrm{NaCl})$ inhibited the growth of cotton seedlings 184 compared with control plants (CK). Compared with salt stress (S) alone, the treatment with 50, 
185100,200 , and $500 \mu \mathrm{M}$ exogenous melatonin reduce the inhibition of cotton seedlings growth 186 under salt stress. Fig. 1B-C shows the trends in plant height and leaf area were quite similar, 187 increasing gradually over time. Under salt stress (S), plant height was significantly reduced 188 compared with that of the control (CK), with decreases of $16.2 \%, 23.5 \%, 22.5 \%$, and $25 \%$ by 3 , 189 6, 9, and $12 \mathrm{~d}$, respectively (Fig. 1B). After the application of melatonin, the height of plants 190 increased first and then decreased with the increase of melatonin concentration. Under $200 \mu \mathrm{M}$ 191 melatonin treatments, the heights of cotton plants across the different periods $(3 \mathrm{~d}, 6 \mathrm{~d}, 9 \mathrm{~d}$, and

$19212 \mathrm{~d}$ ) were highest, $9.87 \mathrm{~cm}, 11.05 \mathrm{~cm}, 12.2 \mathrm{~cm}$, and $14.47 \mathrm{~cm}$, respectively, and compared with 193 S plants, they were significantly increased by $19.4 \%, 21.2 \%, 19.4 \%$, and $25.4 \%$, respectively. 194 However, there was no significant difference, indicating that $200 \mu \mathrm{M}$ melatonin effectively 195 promoted the increase of cotton plant height.

196 Under salt stress, the leaf area was significantly reduced, by $24 \%, 28.7 \%, 25.9 \%$, and $24.9 \%$, 197 compared with CK at 3, 6, 9, and 12 d, respectively (Fig. 1C). When treated with different 198 concentrations of melatonin, the leaf area in cotton leaves showed different trends. When treated 199 with $50 \mu \mathrm{M}$ melatonin at 9, and $12 \mathrm{~d}$, the leaf area of cotton seedlings was significantly higher 200 than that of S plants. When the melatonin concentration was $200 \mu \mathrm{M}$, the increase was greatest. 201 At this concentration, the leaf areas on $3 \mathrm{~d}, 6 \mathrm{~d}, 9 \mathrm{~d}$, and $12 \mathrm{~d}$ were $93.65 \mathrm{~cm}^{2}, 121.16 \mathrm{~cm}^{2}$, $202145.69 \mathrm{~cm}^{2}$, and $178.32 \mathrm{~cm}^{2}$, respectively; compared with S plants, they were significantly 203 increased, by $29.8 \%, 37.2 \%, 31.2 \%$, and $28.8 \%$, respectively, indicating that $200 \mu \mathrm{M}$ melatonin 204 effectively promoted the increase of leaf area.

\section{Exogenous melatonin affects ROS content of cotton seedlings under salt stress}

206 When plants are under stress, high levels of reactive oxygen species $\left(\mathrm{H}_{2} \mathrm{O}_{2}, \mathrm{O}_{2}{ }^{-}\right.$, etc. $)$are 207 accumulated, causing oxidative stress. MDA, a metabolite of membrane lipid peroxidation, can 208 reflect the degree of cellular damage (Farooq et al., 2017).

209 Fig. 2A-2C shows that the trends in contents of $\mathrm{H}_{2} \mathrm{O}_{2}, \mathrm{O}_{2}{ }^{-}$, and superoxide anion production 210 rates of leaves were quite similar, and decreased gradually over time. However, the MDA 211 content increased gradually over time, reaching their highest values at $12 \mathrm{~d}$ (Fig. 2D).

212 Compared with the $\mathrm{CK}$ treatment, the $\mathrm{H}_{2} \mathrm{O}_{2}$ content under the salt stress (S) treatment 213 increased significantly, by $58.1 \%, 33.9 \%, 45.1 \%$, and $37.2 \%$ at $3,6,9$, and $12 \mathrm{~d}$, respectively 214 (Fig. 2A). When treated with melatonin treatments, the $\mathrm{H}_{2} \mathrm{O}_{2}$ content was significantly lower 215 than that of S plants. With exogenous melatonin, $\mathrm{H}_{2} \mathrm{O}_{2}$ content first decreased and then increased 
216 as melatonin concentration increased. Under the $50 \mu \mathrm{M}$ melatonin treatment, the $\mathrm{H}_{2} \mathrm{O}_{2}$ content of 217 cotton leaves was lower than that of S plants during the treatment period, but there was no 218 significant difference; under the 100, 200, and $500 \mu \mathrm{M}$ melatonin treatments at 3, 6, 9, and $12 \mathrm{~d}$, 219 the $\mathrm{H}_{2} \mathrm{O}_{2}$ content was significantly lower than that of $\mathrm{S}$ plants. Among them, the $\mathrm{H}_{2} \mathrm{O}_{2}$ content of 220 cotton leaves decreased most significantly under $200 \mu \mathrm{M}$ melatonin treatment, and the $\mathrm{H}_{2} \mathrm{O}_{2}$ 221 content at 3, 6, 9, and $12 \mathrm{~d}$ was decreased by $30.7 \%, 23.4 \%, 28 \%$, and $26.8 \%$, respectively,

222 223 224 225 226 227 228 229 230 231 232 233 234 235 236

237 238 indicating that $200 \mu \mathrm{M}$ melatonin had the most obvious effect on reducing the $\mathrm{H}_{2} \mathrm{O}_{2}$ content of cotton leaves.

Compared with the CK treatment, the $\mathrm{O}_{2}^{-}$content under the salt stress $(\mathrm{S})$ treatment increased significantly, by $46.8 \%, 24.9 \%, 32.6 \%$, and $32.3 \%$ at 3, 6, 9, and $12 \mathrm{~d}$, respectively (Fig. 2B). When exogenous melatonin was applied, the $\mathrm{O}_{2}{ }^{-}$content first decreased and then increased as melatonin concentration increased. Under the $50 \mu \mathrm{M}$ melatonin treatment, the $\mathrm{O}_{2}{ }^{-}$content of cotton leaves was significantly higher than that of S plants at 3, 9, and $12 \mathrm{~d}$. Under 100, 200 and $500 \mu \mathrm{M}$ melatonin treatments, $\mathrm{O}_{2}^{-}$content was significantly higher than that of S plants at 3, 6, 9, and $12 \mathrm{~d}$, with the $200 \mu \mathrm{M}$ melatonin treatment inducing the most significant decrease in $\mathrm{O}_{2}{ }^{-}$ content. $\mathrm{O}_{2}^{-}$content levels were reduced by $26.8 \%, 15.6 \%, 21 \%$, and $22 \%$, respectively, at 3,6 , 9, and $12 \mathrm{~d}$, compared with S plants, indicating that the $200 \mu \mathrm{M}$ melatonin treatment had the most inhibitory effect on $\mathrm{O}_{2}{ }^{-}$accumulation of cotton leaves. In addition, the trend in the superoxide anion production rate of leaves is similar to that of $\mathrm{O}_{2}{ }^{-}$content, and the results also showed that $200 \mu \mathrm{M}$ melatonin treatment effectively inhibited superoxide anion production in cotton leaves (Fig. 2C).

Compared with CK plants, the MDA content of cotton seedlings under salt stress (S) increased significantly, by $25.2 \%, 28.6 \%, 36.4 \%$, and $40.5 \%$ at $3,6,9$, and $12 \mathrm{~d}$, respectively (Fig. 2D). Under exogenous melatonin, MDA first decreased and then increased as melatonin concentration increased. Under the $50 \mu \mathrm{M}$ melatonin treatment, the MDA content of cotton seedlings was significantly lower than that of S plants only at 3, 6, and $9 \mathrm{~d}$; under the 100,200 , and $500 \mu \mathrm{M}$ melatonin treatments, the MDA content was significantly lower than that of S plants at 3, 6, 9, and $12 \mathrm{~d}$, with MDA decreased most significantly under the $200 \mu \mathrm{M}$ melatonin treatment. The MDA contents at 3, 6, 9, and $12 \mathrm{~d}$ were decreased, by $17 \%, 17.7 \%, 20.1 \%$, and 20\%, compared with S plants, indicating that the $200 \mu \mathrm{M}$ melatonin treatment significantly inhibited the accumulation of MDA content in cotton leaves. 
247 Exogenous melatonin affects antioxidant enzymes of cotton seedlings under salt stress

248 Under adverse conditions, plants use their own enzymatic antioxidant system (i.e., SOD, POD,

249 CAT, and APX) to remove excess ROS so as to protect cells from oxidative damage caused by 250 these conditions (Munns and Tester, 2008).

251 Fig. 3 shows the trends in SOD, POD, CAT, and APX activity levels of leaves under control 252 (CK) and salt stress (S) conditions are quite similar, with no significant change over time under 253 the control (CK) treatment. However, the SOD, POD, and CAT activity levels of leaves under 254 salt stress (S) decreased over time, reaching their lowest values at $12 \mathrm{~d}$.

255 The SOD activity under the salt stress (S) treatment was significantly increased, with SOD 256 activities at 3, 6, 9, and $12 \mathrm{~d}$ that were $46.6 \%, 37.3 \%, 26.1 \%$, and $18.2 \%$ higher than those of CK 257 plants, respectively (Fig. 3A). After applying different concentrations of melatonin, the SOD 258 activity in cotton leaves increased first and then decreased. When treated with 50, 100, and 500 $259 \mu \mathrm{M}$ melatonin at 3, 6, 9, and $12 \mathrm{~d}$, the SOD activity of cotton seedlings was significantly higher 260 than that of S, with the $200 \mu \mathrm{M}$ melatonin treatment having the most obvious effect in increasing 261 SOD activity. The SOD activities at 3, 6, 9, and $12 \mathrm{~d}$ were increased by $11.9 \%, 14.9 \%, 14.2 \%$, 262 and $15.9 \%$, respectively, compared with S plants, indicating that $200 \mu \mathrm{M}$ melatonin had the most 263 obvious effect promoting the SOD activity of cotton leaves.

The POD activity under the salt stress (S) treatment was significantly increased (Fig. 3B), with 265 POD activity levels at 3, 6, 9, and $12 \mathrm{~d}$ that were increased by $103.2 \%, 62 \%, 11.2 \%$, and 10.6\%, 266 respectively, compared with the $\mathrm{CK}$ plants. After applying melatonin at different concentrations, the variation trend of POD was similar to that of SOD. When treated with $50 \mu \mathrm{M}$ melatonin at 9 , and $12 \mathrm{~d}$, the POD activity of cotton seedlings was significantly higher than that of S plants. Under 100, 200, and $500 \mu \mathrm{M}$ melatonin treatments across 3, 6, 9, and $12 \mathrm{~d}$, the POD activity was significantly higher than that of S plants; the increase in POD activity of cotton seedlings was the most significant under the $200 \mu \mathrm{M}$ melatonin treatment. When compared with S plants, The POD activities at 3, 6, 9, and $12 \mathrm{~d}$ were increased by $22.3 \%, 39 \%, 66.3 \%$, and $46.4 \%$, respectively, indicating that $200 \mu \mathrm{M}$ melatonin most obviously promoted the POD activity of cotton leaves.

The CAT activity under the salt stress (S) treatment was significantly increased, and at 3, 6, 9, 275 and $12 \mathrm{~d}$, it was increased by $27.8 \%, 19.9 \%, 14.3 \%$, and $15.7 \%$, respectively, compared with CK plants (Fig. 3C). When treated with $50 \mu \mathrm{M}$ melatonin at 3, 9, and $12 \mathrm{~d}$, the CAT activity of 
278 melatonin treatments at 3, 6, 9, and $12 \mathrm{~d}$, the CAT activity was significantly higher than that of S 279 plants. Among them, the increase in CAT activity was most obvious under the $200 \mu \mathrm{M}$ 280 melatonin treatment. The CAT activity levels at 3, 6, 9, and $12 \mathrm{~d}$ were $11.5 \%, 13 \%, 11.8 \%$, and $28114.4 \%$ higher, respectively, than those of S plants, indicating that $200 \mu \mathrm{M}$ melatonin most 282 obviously promoted the CAT activity of cotton leaves.

283 The APX activity under the salt stress (S) treatment was significantly increased, and at 3, 6, 9, 284 and $12 \mathrm{~d}$, it was increased by $125.9 \%, 104.2 \%, 67.2 \%$, and $37.1 \%$, respectively, compared with 285 CK plants (Fig. 3D). After applying melatonin, the APX activity increased. Under the $200 \mu \mathrm{M}$ 286 melatonin treatment, the APX activity levels at 3, 6, 9, and $12 \mathrm{~d}$ were $12.9 \%, 13.5 \%, 16.5 \%$, and

$28720.2 \%$ higher, respectively, than those of S plants, indicating that $200 \mu \mathrm{M}$ melatonin most 288 obviously promoted the APX activity of cotton leaves.

289 Exogenous melatonin affects AsA and GSH contents of cotton seedlings under salt stress

290 Fig. 4 shows the trends in AsA and GSH content levels under control (CK) ere quite uniform, 291 with no significant change over time under control (CK) conditions. However, the AsA and GSH 292 content levels of leaves under salt stress (S) decreased over time, reaching their lowest values at $29312 \mathrm{~d}$. The AsA content under the salt stress (S) treatment was significantly increased, and the 294 AsA content at 3, 6, 9, and $12 \mathrm{~d}$ increased by $30.8 \%, 25.2 \%, 15.7 \%$, and $15.9 \%$, respectively, 295 compared with CK plants (Fig. 4A). Under the $50 \mu \mathrm{M}$ melatonin treatment, the AsA content was 296 higher than that of S plants throughout the treatment period, but there was no significant 297 difference. Under the 100 and $500 \mu \mathrm{M}$ melatonin treatments, the AsA content was significantly 298 higher than that of S plants at 3, 6, and $12 \mathrm{~d}$, with the most obvious increase under the $200 \mu \mathrm{M}$ 299 melatonin treatment. The AsA contents at 3, 6, 9, and $12 \mathrm{~d}$ were increased by $10.2 \%, 10 \%$, $11.4 \%$, and $12.2 \%$ compared with S plants; these differences were significant, indicating that 200 $\mu \mathrm{M}$ melatonin treatment effectively increased the AsA content of cotton leaves.

The GSH content under the salt stress (S) treatment was significantly increased, and the GSH 303 content at 3, 6, 9, and $12 \mathrm{~d}$ increased by $20.7 \%, 8.9 \%, 6.5 \%$, and $7.9 \%$, respectively, compared with CK plants (Fig. 4B). Under the $50 \mu \mathrm{M}$ melatonin treatment, the GSH content was 305 significantly higher than that of S plants at 3,6, and $9 \mathrm{~d}$; under the 100,200 , and $500 \mu \mathrm{M}$ melatonin treatments, the GSH content was significantly higher than that of S plants at 3, 6, 9, and $12 \mathrm{~d}$; among these treatments, the increase effect was the most obvious under the $200 \mu \mathrm{M}$ melatonin treatment. The GSH content levels at 3, 6, 9, and $12 \mathrm{~d}$ were increased by $23 \%, 23.3 \%$, 
309

$20.3 \%$, and $19.8 \%$ respectively, compared with S plants; these significant differences indicate that $200 \mu \mathrm{M}$ melatonin treatment effectively increased the GSH content of cotton leaves.

\section{Exogenous melatonin affects organic osmotic substance content of cotton seedlings under} salt stress

Salt stress can cause drought stress to plants. To prevent water loss, plants often accumulate various substances to increase the concentrations of cellular fluids. Soluble sugars and proteins are important osmotic regulators in plants (Kerepesi and Galiba, 2000; Yang and Guo, 2018).

Fig. 5 shows the trends in content of soluble sugar and protein in cotton leaves under control (CK) were quite uniform, increasing gradually over time, reaching their maximum values at 12 d. The soluble sugar content under the salt stress (S) treatment was significantly reduced, with soluble sugar contents of leaves at 3, 6, 9, and $12 \mathrm{~d}$ decreased by $58.5 \%, 52.2 \%, 27.5 \%$, and 33.3\%, respectively, compared with CK plants (Fig. 5A). Under exogenous melatonin, the soluble sugar content first increased and then decreased as melatonin concentration increased. Under the $50 \mu \mathrm{M}$ melatonin treatment, the soluble sugar content of cotton seedlings was significantly higher than that of S plants only at $3 \mathrm{~d}$; under the $100 \mu \mathrm{M}$ melatonin treatment, the soluble sugar content was significantly higher than that of S plants at 3,6, and $12 \mathrm{~d}$. Under the $500 \mu \mathrm{M}$ melatonin treatment, the soluble sugar content was significantly higher than that of $\mathrm{S}$ plants at $6 \mathrm{~d}$. Under the $200 \mu \mathrm{M}$ melatonin treatment, the soluble sugar content of cotton leaves increased most significantly. The soluble sugar contents at 3, 6, 9, and $12 \mathrm{~d}$ corresponded to significant increases of $91.7 \%, 72.7 \%, 28.2 \%$, and $38.4 \%$, respectively, compared with S plants. The $200 \mu \mathrm{M}$ melatonin treatment most obviously promoted the soluble sugar content of cotton leaves.

Compared with the CK treatment, the soluble protein content under the salt stress (S) treatment was significantly reduced, and the soluble protein content at 3, 6, 9, and $12 \mathrm{~d}$ decreased by $8.7 \%, 15.3 \%, 9.4 \%$, and $16.4 \%$, respectively (Fig. 5B). Under exogenous melatonin, the soluble protein content first increased and then decrease as melatonin concentration increased. Under the $50 \mu \mathrm{M}$ melatonin treatment, the soluble protein content of cotton leaves was significantly higher than that of S plants only at $6 \mathrm{~d}$; under the 100 and $500 \mu \mathrm{M}$ melatonin treatments, the soluble protein content was significantly higher than that of S plants at 6, 9, and $12 \mathrm{~d}$. The soluble protein content of cotton leaves increased most significantly under the $200 \mu \mathrm{M}$ melatonin treatment, and the soluble protein contents at 3, 6, 9, and $12 \mathrm{~d}$ corresponded to 
341 significant increases of $7.1 \%, 17.5 \%, 9.1 \%$, and $18.1 \%$, respectively, compared with S plants,

342 indicating that $200 \mu \mathrm{M}$ melatonin effectively increased soluble protein content in cotton leaves.

\section{Discussion}

344 Salt damage is a major factor limiting the growth and yield formation of cotton seedlings (Munns

345

346

347

348

349

350

351

352

353

354

355

356

357

358

359

360

361

362

363

364

365

366

367

368

369

370

371 and Tester, 2008). Salt stress can disrupt ion homeostasis in plants, cause ion poisoning, reduce the water and osmotic potentials of cells, and induce osmotic stress (Abbasi et al., 2016). When plants are subjected to salt stress, the most common major phenomenon is growth inhibition (Towfique et al., 2013). Melatonin is a highly conserved and physiologically active indoleamine plant hormone that can effectively alleviate damage caused by abiotic stress to plants (Arnao and Hernández-Ruiz, 2015). Several studies have reported that melatonin enhances abiotic stress resistance in naked oat (Gao et al., 2019), cucumber (Zhang et al., 2014), maize (Li et al., 2019c), and Citrus aurantium (Kostopoulou et al., 2015). In this study, melatonin treatment increased plant height and leaf area of cotton seedlings, which is consistent with the results of Gao et al. (2019), who found that melatonin alleviates oxidative stress in naked oat under alkaline conditions.

Plant cells can maintain low ROS levels under normal growth conditions because the antioxidant enzyme system in the body achieves a balance between the elimination of ROS and the production of ROS. Under salt stress, plants accumulate high levels of ROS owing to excessive $\mathrm{Na}^{+}$accumulation, which destroys the ROS clearance systems of plants, leading to membrane lipid peroxidation, increased membrane permeability, and structural damage to membranes and membrane lipids (Zhan et al., 2019). The content of MDA, the final product of membrane lipid peroxidation, increased ROS accumulation under salt stress (Hernandez et al., 2000; Møller et al., 2007). In the present study, the $\mathrm{H}_{2} \mathrm{O}_{2}, \mathrm{O}_{2}^{-}$, and MDA contents of cotton seedlings were remarkably increased by $\mathrm{NaCl}$ treatment. Over time, $\mathrm{H}_{2} \mathrm{O}_{2}$ and $\mathrm{O}_{2}{ }^{-}$contents decreased, while MDA content increased, indicating that high levels of active oxygen were produced in cotton under salt stress, leading to membrane lipid peroxidation damage. The application of different concentrations of melatonin significantly reduced $\mathrm{H}_{2} \mathrm{O}_{2}, \mathrm{O}_{2}^{-}$, and MDA contents (Figure 2). This is consistent with findings reported for tea (Li et al., 2019b), naked oat (Gao et al., 2019), and rubber trees (Yang et al., 2020) under cold, salt, and drought stresses. Melatonin directly scavenges $\mathrm{H}_{2} \mathrm{O}_{2}$ and enhances the activities of antioxidant enzymes to detoxify $\mathrm{H}_{2} \mathrm{O}_{2}$ indirectly; additionally, water balance is regulated under drought conditions by 
372 up-regulating the expression of melatonin synthesis genes (Li et al., 2015). This is probably

373 because melatonin, as an electron donor, directly reacts with $\mathrm{H}_{2} \mathrm{O}_{2}$, hydroxyl radicals $(\cdot \mathrm{OH})$, and

374 related molecules, and melatonin is itself oxidized to an indole cation free radical, which in turn

375 reacts with intracellular $\mathrm{O}_{2}$ and further oxidizes to stable $\mathrm{N}$-acetyl- $\mathrm{N}$-formyl-5-methoxykinamine

376 (5-MAFK). Melatonin induced MAPK cascade related to $\mathrm{H}_{2} \mathrm{O}_{2}$ signaling pathway, promoted the

377 expression of TFs WRKY genes related to salt stress (Gao et al., 2019) and alleviate membrane

378 lipid peroxidation under stress (Ye et al., 2016; Cui et al., 2017), thereby increasing the tolerance

379 of plants to salt. Thus, melatonin improves the ability of cotton seedlings to scavenge ROS and

380 reduces membrane lipid peroxidation damage to cells. Moreover, the effect of melatonin is

381 dependent upon its concentration. Among treatments, the $200 \mu \mathrm{M}$ melatonin treatment exhibited

382 the strongest ability to enhance ROS scavenging.

383 Plants can protect their cells from oxidative damage by removing excess ROS under adverse

384 conditions through enzymatic and non-enzymatic antioxidant systems; the main antioxidant

385 enzymes in plants are SOD, POD, CAT, and APX (Li et al., 2019a). Application of melatonin to

386 tomato plants has been shown to minimize the negative impact of drought by regulating the

387 antioxidant system, which reduces the abundance of toxic cells in plants, resulting in stronger,

388 more drought-tolerant seedlings (Liu et al., 2015a; Li et al., 2019b). Melatonin could improve

389 salt resistance by regulating the corresponding genes encoding antioxidant enzymes in cucumber

390 under high salinity (Zhang et al., 2014). In the present study, the activities of SOD, POD, CAT,

391 and APX in cotton seedlings increased significantly under salt stress and gradually decreased

392 throughout treatment time. In the early stage of salt stress, CAT activity in cotton seedlings

393 increased rapidly, but decreased gradually with time, indicating that salt stress inhibited CAT

394 activity. After applying different concentrations of melatonin, the activity levels of SOD, POD,

395 CAT, and APX were significantly increased (Figure 3). These results were consistent with

396 previous studies. Melatonin has strong antioxidant activity and increases antioxidant enzyme

397 activity of cotton seeds and watermelon seedlings, thus reducing peroxidative damage

398 (Castañares and Bouzo, 2019; Chen et al., 2019; Xiao et al., 2019). This may have been caused

399 by exogenous melatonin upregulating the expression of genes related to antioxidant enzymes and

400 reducing the degradation of biological macromolecules to improve the activity of antioxidant

401 enzymes (Zhang et al., 2014). Exogenous melatonin significantly reduced malondialdehyde

402 content and markedly increased the expression of antioxidant genes in melon (Zhang et al., 
403 2017), wheat (Sun et al., 2018), hickory (Wang et al., 2019), and tea trees (Li et al., 2019b) under 404 abiotic stress. In turn, this may thus have improved the ability of plants to remove ROS while 405 alleviating salt stress in cotton seedlings caused by oxidative stress. Similarly, the effect of 406 melatonin is dependent on its concentration. Among the treatments employed, the $200 \mu \mathrm{M}$ 407 melatonin treatment had the most significant effect on the promotion of antioxidant enzymes in 408 cotton seedlings, which is consistent with the results of Gong et al. (2017), who found that 409 melatonin alleviates oxidative stress in Malus hupehensis under alkaline conditions.

410 Excessive ROS produced by plants under stress conditions are managed by the non-enzymatic 411 systems of plants to protect their cells from oxidative damage (Manchester et al., 2015). AsA and $412 \mathrm{GSH}$ are the main reducing substances in plants, both of which can effectively remove excess 413 ROS and $\mathrm{H}_{2} \mathrm{O}_{2}$ through the AsA-GSH cycle, thereby reducing damage to plants caused by 414 adverse conditions (Bybordi, 2012). In tomato leaves under salt and alkali stress, AsA-GSH 415 cycle components, including ascorbate peroxidase (APX), dehydroascorbate reductase (DHAR), 416 and glutathione reductase (GR), were expressed at higher levels and played an important role in 417 scavenging ROS (Gong et al., 2013). In the present study, the AsA and GSH contents of cotton seedling leaves increased significantly under salt stress and gradually decreased throughout treatment time. The decrease in AsA content indicated that some AsA was oxidized to dehydroascorbic acid (DHA) under salt stress. The decrease in GSH is most likely owing to

421 GSH's involvement in ROS scavenging as a substrate for glutathione oxidase (GPX) or 422 glutathione transferase (GST). After the application of different concentrations of melatonin, the 423 AsA and GSH contents of each treatment increased significantly (Figure 4). GSH exists in most 424 organelles in cells and protects plants from oxidative damage caused by adversity stress (Gill and 425 Tuteja, 2010). In Citrus aurantium, exogenous melatonin can effectively increase the content of 426 reducing substances, such as phenols, AsA, and GSH, under salt stress and alleviate oxidative 427 damage induced by salt stress (Kostopoulou et al., 2015). Exogenous melatonin enhances the 428 tolerance of tomato and cucumber seedlings to stress by stimulating the AsA-GSH cycle enzyme 429 activity and inducing the accumulation of AsA and GSH (Liu et al., 2015b; Wang et al., 2016; 430 Yin et al., 2019). This may be caused by melatonin increasing monoascorbate reductase 431 (MDHAR), DHAR, and GR activity levels and accelerating the regeneration of AsA and GSH, 432 thereby ensuring relatively high concentrations of AsA and GSH in cotton under salt stress, and 433 enhancing resistance to salt stress. Thus, melatonin alleviated oxidative stress caused by salt 
434 stress in cotton seedlings by increasing the content of reducing substances (i.e., AsA and GSH)

435 and the activity of antioxidant enzymes. In addition, the relationship between melatonin and its

436 effect depended on its concentration, and the $200 \mu \mathrm{M}$ melatonin treatment most obviously

437 promoted AsA and GSH, which is consistent with the findings of similar previous studies (Shi et 438 al., 2014; Zhao et al., 2016).

439 Osmotic regulation is a key self-defense mechanism produced by plants under stress. Plants 440 produce high levels of osmotic regulating substances (e.g., soluble sugars and proteins) to 441 increase cytoplasmic solute concentrations, increase cell osmotic pressure to reduce water 442 potential, and reduce cell water loss (Verbruggen and Hermans, 2008). Under salt stress, plants 443 maintain necessary nutrients for their metabolic development by increasing osmotic regulators, 444 thereby reducing damage caused by salt stress. A previous study has shown that adverse stress 445 reduces the soluble sugar content of maize seedlings, while melatonin treatment increases 446 soluble sugar content; soluble sugars participate in osmotic regulation of plants and alleviate the 447 inhibitory effect of stress on maize growth (Li et al., 2019c). Most soluble proteins in plants are 448 enzymes involved in various metabolisms (Acostamotos et al., 2017). In this study, the soluble 449 sugar and soluble protein contents of cotton seedling leaves significantly decreased under salt 450 stress. Over time, the contents of soluble sugars and proteins first increased and then decreased, 451 possibly as a consequence of salt stress. High levels of ROS destabilize sugars and proteins or 452 affect their synthesis and metabolism pathways, causing the content of soluble sugars and 453 proteins to decrease. After applying different concentrations of melatonin, the content of soluble 454 sugar and protein in each treatment increased significantly, probably because melatonin 455 promoted the synthesis of heat shock proteins in cotton seedlings and protected proteins from 456 damage, indicating that melatonin participated in the osmotic adjustment of cotton seedlings 457 (Figure 5). These findings are similar to those presented by Gao et al. (2019). Melatonin 458 treatment can increase the soluble protein content of plants, alleviate damage to soybean and 459 cotton seeds under drought and salt stress, and improve plant resistance to stress (Gao et al., 460 2019; Chen et al., 2020). Similarly, exogenous melatonin can alleviate osmotic stress caused by 461 drought by increasing soluble sugar and soluble protein content of rapeseed, and it thus improves 462 the growth of seedlings ( $\mathrm{Li}$ et al., 2018b). The effect of melatonin on the osmotic adjustment of 463 cotton seedlings was accomplished by increasing the content of soluble sugars and proteins, thus 464 relieving the osmotic stress caused by high salt. Soluble sugar and protein contents under the 200 
$465 \mu \mathrm{M}$ melatonin treatment increased the most, indicating that the effect of melatonin is related to

466 its concentration, which is consistent with the results of Li et al. (2018b), who showed that

467 exogenous melatonin alleviates osmotic stress in rapeseed plants under drought conditions.

\section{Conclusions}

469 Exogenous application of melatonin can improve the ROS scavenging capacity of cotton plants

470 under salt stress by enhancing their antioxidant capacity. Additionally, melatonin treatment can

471 alleviate osmotic stress by promoting the accumulation of osmoregulatory substances such as

472 soluble sugars and proteins. Ultimately, exogenous melatonin could be used to facilitate

473 development of cotton seedlings under salt stress, thereby alleviating salt stress in cotton

474 seedlings. The $200 \mu \mathrm{M}$ melatonin treatment is the most effective in promoting cotton seedling

475 growth and salt tolerance in this experiment. The result provides a theoretical basis for melatonin

476 to alleviate salt stress caused by unreasonable irrigation, fertilization and climate change. Further

477 investigations need to be done to explore the molecular mechanism of exogenous melatonin

478 regulating cotton seedlings under salt stress.

\section{Acknowledgements}

480 The authors are grateful to the anonymous reviewers for their valuable comments and 481 suggestions.

482 References

483 Abbasi H, Jamil M, Haq A, Ali S, Ahmad R, Malik Z, Parveen. 2016. Salt stress

484 manifestation on plants, mechanism of salt tolerance and potassium role in alleviating it: a

485 review. Zemdirbyste-Agriculture 103(2): 229-238 DOI 10.13080/z-a.2016.103.030

486 Acostamotos JR, Ortuno MF, Bernalvicente A, Diazvivancos P, Sanchezblanco MJ,

487 Hernandez JA. 2017. Plant responses to salt stress: adaptive mechanisms. Agronomy 7(1) DOI

488 10.3390/agronomy7010018

489 Afreen F, Zobayed SM, Kozai T. 2006. Melatonin in Glycyrrhiza uralensis: response of plant

490 roots to spectral quality of light and UV-B radiation. Journal of Pineal Research 41(2): 108-115

491 DOI 10.1111/j.1600-079X.2006.00337.x

492 Ahammed GJ, Xu W, Liu A, Chen SC. 2019. Endogenous melatonin deficiency aggravates

493 high temperature-induced oxidative stress in Solanum lycopersicum L. Environmental and

494 Experimental Botany 303-311 DOI 10.1016/j.envexpbot.2018.06.006 
495 Arnao MB, Hernández-Ruiz J. 2015. Functions of melatonin in plants: a review. Journal of 496 Pineal Research 59(2): 133-150 DOI 10.1111/jpi.12253

497 Arnao MB, Hernández-Ruiz J. 2018. Melatonin and its relationship to plant hormones. Annals 498 of Botany 121(2):195-207 DOI 10.1093/aob/mcx114

499 Bybordi A. 2012. Effect of ascorbic acid and silicium on photosynthesis, antioxidant enzyme 500 activity, and fatty acid contents in canola exposure to salt stress. Journal of Integrative 501 Agriculture 11(10): 1610-1620 DOI 10.1016/S2095-3119(12)60164-6

502 Byeon Y, Park S, Kim YS, Park DH, Lee S, Back K. 2012. Light-regulated melatonin 503 biosynthesis in rice during the senescence process in detached leaves. Journal of Pineal 504 Research 53:107-111 DOI 10.1111/j.1600-079X.2012.00976.x

505 Cao L, Jin XJ, Zhang YX. 2019. Melatonin confers drought stress tolerance in soybean 506 (Glycine max L.) by modulating photosynthesis, osmolytes, and reactive oxygen metabolism.

507 Photosynthetica 57(3): 812-819 DOI 10.32615/ps.2019.100

508 Castañares J.L, Bouzo CA. 2019. Effect of exogenous melatonin on seed germination and 509 seedling growth in melon (Cucumis melo L.) under salt stress. Horticultural Plant Journal 5(2): 510 79-87 DOI 10.1016/j.hpj.2019.01.002

511 Chen L, Liu LT, Lu B, Ma TT, Jiang D, Li J, Zhang K, Sun HC, Zhang YJ, Bai ZY, Li CD. 512 2020. Exogenous melatonin promotes seed germination and osmotic regulation under salt stress 513 in cotton (Gossypium hirsutum L.). PloS ONE 15(1) DOI 10.1371/journal.pone.0228241

514 Chen L, Liu LT, Ma TT, Jiang D, Sun HC, Zhang YJ, Zhang K, Bai ZY, Li CD. 2019.

515 Effects of melatonin on the antioxidant enzyme activities and seed germination of cotton 516 (Gossypium hirsutum L.) under salt-stress conditions. Cotton Science 31(5): 438-447. (in 517 chinese) DOI 10.11963/1002-7807.cllcd.20190905

518 Cui GB, Zhao XX, Liu SD, Sun FL, Zhang C, Xi YJ. 2017. Beneficial effects of melatonin in 519 overcoming drought stress in wheat seedlings. Plant Physiology and Biochemistry 118: 138-149 520 DOI 10.1016/j.plaphy.2017.06.014

521 Dubbels R, Reiter R J, Klenke E, Goebel A, Schnakenberg E, Ehlers C, Schiwara HW, 522 Schloot W. 1995. Melatonin in edible plants identified by radioimmunoassay and by high 523 performance liquid chromatography-mass spectrometry. Journal of Pineal Research 18(1): 28-31 524 DOI 10.1111/j.1600-079X.1995.tb00136.x 
525 Farooq M, Gogoi N, Hussain M, Barthakur S, Paul S, Bharadwaj N, Migdadi HM,

526 Alghamdi SS, Siddique K. 2017. Effects, tolerance mechanisms and management of salt stress

527 in grain legumes. Plant Physiology and Biochemistry 199-217 DOI

528 10.1016/j.plaphy.2017.06.020

529 Gao QH, Jia SS, Miao YM, Lu XM, Li HM. 2016. Effects of exogenous melatonin on nitrogen 530 metabolism and osmotic adjustment substances of melon seedlings under sub-low temperature.

531 The Journal of Applied Ecology 27(2): 519-524

532 Gao WY, Feng Z, Bai QQ, He JJ, Wang YJ. 2019. Melatonin-mediated regulation of growth 533 and antioxidant capacity in salt-tolerant Naked Oat under salt Stress. International Journal of 534 Molecular Sciences 20(5): 1176 DOI 10.3390/ijms20051176

535 Gill SS, Tuteja N. 2010. Reactive oxygen species and antioxidant machinery in abiotic stress 536 tolerance in crop plants. Plant Physiology and Biochemistry 48(12): 909-930 DOI

537 10.1016/j.plaphy.2010.08.016

538 Gong B, Wen D, VandenLangenberg K, Wen M, Yang FJ, Shi QH, Wang XF. 2013.

539 Comparative effects of $\mathrm{NaCl}$ and $\mathrm{NaHCO}_{3}$ stress on photosynthetic parameters, nutrient

540 metabolism, and the antioxidant system in tomato leaves. Scientia Horticulturae 157: 1-12 DOI

541 10.1016/j.scienta.2013.03.032

542 Gong XQ, Shi ST, Dou FF, Song Y, Ma FW. 2017. Exogenous melatonin alleviates alkaline 543 stress in Malus hupehensis Rehd. by regulating the biosynthesis of polyamines. Molecules 22(9):

5441542 DOI 10.3390/molecules22091542

545 Hardeland R. 2016. Melatonin in plants - diversity of levels and multiplicity of functions.

546 Frontiers in Plant Science 198-198 DOI 10.3389/fpls.2016.00198

547 Hattori A, Migitaka H, Iigo M, Itoh M, Yamamoto K, Ohtanikaneko R, Hara M, Suzuki T,

548 Reiter RJ. 1995. Identification of melatonin in plants and its effects on plasma melatonin levels 549 and binding to melatonin receptors in vertebrates. Iubmb Life 35(3): 627-634

550 Hernandez JA, Jimenez A, Mullineaux P, Sevilla F. 2000. Tolerance of pea (Pisum sativum

551 L.) to long-term salt stress in associated with induction of antioxidant defenses. Plant, Cell \&

552 Environment 23: 853-862 DOI 10.1046/j.1365-3040.2000.00602.x

553 Hu T, Zhang GX, Zheng FC, Cao Y. 2018. Research Progress in Plant Salt Stress Response.

554 Molecular Plant Breeding 16 (09): 3006-3015 DOI 10.1327/j.mpb.016.003006 
555 Kaya C, Okant M, Ugurlar F, Alyemeni MN, Ashraf M, Ahmad P. 2019. Melatonin-

556 mediated nitric oxide improves tolerance to cadmium toxicity by reducing oxidative stress in 557 wheat plants. Chemosphere 627-638 DOI 10.1016/j.chemosphere.2019.03.026

558 Kerepesi I, Galiba G. 2000. Osmotic and salt stress-induced alteration in soluble carbohydrate 559 content in wheat seedlings. Crop Science 40(2): 482-487 DOI 10.2135/cropsci2000.402482x

560 Kolar J, Machackova I. 2005. Melatonin in higher plants: occurrence and possible functions.

561 Journal of Pineal Research 39(4): 333-341 DOI 10.1111/j.1600-079X.2005.00276.X

562 Kostopoulou Z, Therios I, Roumeliotis E, Kanellis AK, Molassitotis A. 2015. Melatonin

563 combined with ascorbic acid provides salt adaptation in Citrus aurantium L. seedlings. Plant

564 Physiology and Biochemistry 86: 155-165 DOI 10.1016/j.plaphy.2014.11.021

565 Li C, Tan DX, Liang D, Chang C, Jia DF, Ma FW. 2015. Melatonin mediates the regulation

566 of ABA metabolism, free-radical scavenging, and stomatal behaviour in two Malus species under

567 drought stress. Journal of Experimental Botany 66(3) DOI 10.1093/jxb/eru476

568 Li JH, Arkorful E, Cheng SY, Zhou QQ, Li H, Chen X, Sun K, Li XH. 2018a. Alleviation of

569 cold damage by exogenous application of melatonin in vegetatively propagated tea plant

570 (Camellia sinensis (L.) O. Kuntze). Scientia Horticulturae 238: 356-362 DOI

571 10.1016/j.scienta.2018.04.068

572 Li JH, Yang YQ, Sun K, Chen Y, Chen X, Li XH. 2019b. Exogenous melatonin enhances

573 cold, salt and drought stress solerance by improving antioxidant defense in tea plant (Camellia

574 sinensis (L.) O. Kuntze). Molecules 24(9): 1826 DOI 10.3390/molecules24091826

575 Li JJ, Zeng L, Cheng Y, Lu GY, Fu GP, Ma HQ, Liu QY, Zhang XK, Zou XL, Li CS.

576 2018b. Exogenous melatonin alleviates damage from drought stress in Brassica napus

577 L.(rapeseed) seedlings. Acta physiologiae Plantarum 40(3): 43 DOI 10.1007/s11738-017-2601-8

578 Li JP, Liu J, Zhu TT, Zhao C, Li LY, Chen M. 2019a. The role of melatonin in salt stress

579 responses. International Journal of Molecular Sciences 20(7): 1735 DOI 10.3390/ijms20071735

580 Li ZG, Xu Y, Bai LK, Zhang SK, Wang Y. 2019c. Melatonin enhances thermotolerance of

581 maize seedlings (Zea mays L.) by modulating antioxidant defense, methylglyoxal detoxification,

582 and osmoregulation systems. Protoplasma 256(2): 471-490 DOI 10.1007/s00709-018-1311-4

583 Liang WJ, Ma XL, Wan P, Liu LY. 2018. Plant salt-tolerance mechanism: a review.

584 Biochemical and Biophysical Research Communications 495(1): 286-291 DOI

585 10.1016/j.bbrc.2017.11.043 
586 Liu JL, Wang WX, Wang LY, Sun Y. 2015a. Exogenous melatonin improves seedling health

587 index and drought tolerance in tomato. Plant Growth Regulation 77(3): 317-326 DOI

$588 \quad 10.1007 / \mathrm{s} 10725-015-0066-6$

589 Liu N, Jin ZY, Wang SS, Gong B, Wen D, Wang XF, Wei M, Shi QH. 2015b. Sodic alkaline

590 stress mitigation with exogenous melatonin involves reactive oxygen metabolism and ion

591 homeostasis in tomato. Scientia Horticulturae 181: 18-25 DOI 10.1016/j.scienta.2014.10.049

592 Luo Z, Liu H, Li WP, Zhao Q, Dai JL, Tian LW, Dong HZ. 2018. Effects of reduced nitrogen

593 rate on cotton yield and nitrogen use efficiency as mediated by application mode or plant density.

594 Field Crops Research 218: 150-157 DOI 10.1016/j.fcr.2018.01.003

595 Manchester LC, Cotomontes A, Boga JA, Andersen LPH, Zhou Z, Galano A, Vriend J,

596 Tan DX, Reiter RJ. 2015. Melatonin: An ancient molecule that makes oxygen metabolically

597 tolerable. Journal of Pineal Research 59, 403-419 DOI 10.1111/jpi.12267

598 Mengel K, Robin P, Salsac L. 1983. Nitrate reductase activity in shoots and roots of maize

599 seedlings as affected by the form of nitrogen nutrition and the $\mathrm{pH}$ of the nutrient solution. Plant

600 Physiology 71(3): 618-622 DOI 10.1104/pp.71.3.618

601 Møller IM, Jensen PE, Hansson A. 2007. Oxidative modifications to cellular components in

602 plants. Annual Review of Plant Biology 58: 459-481 DOI

603 10.1146/annurev.arplant.58.032806.103946

604 Munns R, Tester M. 2008. Mechanisms of salinity tolerance. Annual Review of Plant Biology

605 59(1): 651-681 DOI 10.1146/annurev.arplant.59.032607.092911

606 Munns R. 2002. Comparative physiology of salt and water stress. Plant, Cell \& Environment

607 25(2): 239-250 DOI 10.1046/j.0016-8025.2001.00808.X

608 Murch SJ, Krishnaraj S, Saxena PK. 2000. Tryptophan is a precursor for melatonin and

609 serotonin biosynthesis in in vitro regenerated St. John's wort (Hypericum perforatum L. cv.

610 Anthos) plants. Plant Cell Reports 19(7): 698-704 DOI 10.1007/s002990000206

611 Okazaki M, Ezura H. 2009. Profiling of melatonin in the model tomato (Solanum lycopersicum

612 L.) cultivar Micro-Tom. Journal of Pineal Research 46(3):338-343 DOI 10.1111/j.1600-

613 079X.2009.00668.x

614 Oladi E, Mohamadi M, Shamspur T, Mostafavi A. 2014. Spectrofluorimetric determination of

615 melatonin in kernels of four different Pistacia varieties after ultrasound-assisted solid-liquid 
616 extraction. Spectrochimica Acta Part A: Molecular and Biomolecular Spectroscopy 326-329

617 DOI 10.1016/j.saa.2014.05.010

618 Parida A, Das AB. 2005. Salt tolerance and salinity effects on plants: a review. Ecotoxicology

619 and Environmental Safety 60(3): 324-349 DOI 10.1016/j.ecoenv.2004.06.010

620 Park HJ, Kim WY, Yun DJ. 2016. A new insight of salt stress signaling in plant. Molecules

621 and Cells 39(6) DOI 10.14348/molcells.2016.0083

622 Park SK, Lee DE, Jang H, Byeon Y, Kim YS, Back K. 2012. Melatonin-rich transgenic rice

623 plants exhibit resistance to herbicide-induced oxidative stress. Journal of Pineal Research 54(3)

624 DOI 10.1111/j.1600-079X.2012.01029.x

625 Park S, Lee K, Kim YS, Back K. 2012. Tryptamine 5-hydroxylase-deficient Sekiguchi rice

626 induces synthesis of 5-hydroxytryptophan and $\mathrm{N}$-acetyltryptamine but decreases melatonin

627 biosynthesis during senescence process of detached leaves. Journal of Pineal Research

628 52(2):211-216 DOI 10.1111/j.1600-079X.2011.00930.x

629 Reiter RJ, Tan DX, Osuna C, Gitto E. 2000. Actions of melatonin in the reduction of oxidative

630 stress. Journal of Biomedical Science 7(6): 444-458 DOI 10.1007/BF02253360

631 Pieri C, Marra M, Moroni F, Recchioni R, Marcheselli F. 1994. Melatonin: a peroxyl radical

632 scavenger more effective than vitamin E. Life Sciences 55(15): 271-276 DOI 10.1016/0024-

633 3205(94)00666-0

634 Posmyk MM, Kuran H, Marciniak K, Janas KM. 2008. Presowing seed treatment with

635 melatonin protects red cabbage seedlings against toxic copper ion concentrations. Journal of

636 Pineal Research 45(1): 24-31 DOI 10.1111/j.1600-079X.2007.00552.x

637 Ren S, Rutto L, Katuuramu D. 2019. Melatonin acts synergistically with auxin to promote

638 lateral root development through fine tuning auxin transport in Arabidopsis thaliana. PloS ONE

639 14(8) DOI 10.1371/journal.pone.0221687

640 Saeteaw M, Johns J, Johns N P, Subongkot S. 2013. Serum melatonin levels and antioxidant

641 capacities after consumption of pineapple, orange, or banana by healthy male volunteers. Journal

642 of Pineal Research 55(1): 58-64 DOI 10.1111/jpi.12025

643 Sharma A, Zheng BS. 2019. Melatonin mediated regulation of drought stress: physiological and

644 molecular aspects. Plants 8(7) DOI 10.3390/plants8070190

645 Shi HT, Jiang C, Ye TT, Tan DX, Reiter RJ, Zhang H, Liu RY, Chan ZL. 2015.

646 Comparative physiological, metabolomic, and transcriptomic analyses reveal mechanisms of 
647 improved abiotic stress resistance in bermudagrass [Cynodon dactylon (L). Pers.] by exogenous

648 melatonin. Journal of Experimental Botany 66(3), 681-694 DOI 10.1093/jxb/eru373

649 Sun LY, Li XN, Wang ZS, Sun ZW, Zhu XC, Liu SQ, Song FB, Liu FL, Wang YJ. 2018.

650 Cold priming induced tolerance to subsequent low temperature stress is enhanced by melatonin

651 application during recovery in wheat. Molecules 23(5) DOI 10.3390/molecules23051091

652 Tan DX, Manchester LC, Liu XY, Rosalescorral S, Acunacastroviejo D, Reiter RJ. 2013.

653 Mitochondria and chloroplasts as the original sites of melatonin synthesis: a hypothesis related to

654 melatonin's primary function and evolution in eukaryotes. Journal of Pineal Research 54(2):

655 127-138 DOI 10.1111/jpi.12026

656 Tiryaki I, Keles H. 2012. Reversal of the inhibitory effect of light and high temperature on

657 germination of Phacelia tanacetifolia seeds by melatonin. Journal of Pineal Research 52(3): 332-

658339 DOI 10.1111/j.1600-079X.2011.00947.X

659 Towfique NM, Hafiz FB, Sen MK. 2013. The mechanism of soil salinity and plant response: an

660 update review. Journal of Agricultural Science and Technology 2(1)

661 Verbruggen N, Hermans C. 2008. Proline accumulation in plants: a review. Amino Acids 35(4):

662 753-759. 19 DOI 10.1007/s00726-008-0061-6

663 Wang JF, Chen JJ, Sharma A, Tao SC, Zheng BS, Landi M, Yuan HW, Yan DL. 2019.

664 Melatonin stimulates activities and expression level of antioxidant enzymes and preserves

665 functionality of photosynthetic apparatus in hickory plants (Carya cathayensis Sarg.) under

666 PEG-Promoted Drought. Agronomy 9(11) DOI 10.3390/agronomy9110702

667 Wang L, Liu J, Wang WX, Sun Y. 2016. Exogenous melatonin improves growth and

668 photosynthetic capacity of cucumber under salinity-induced stress. Photosynthetica 54(1): 19-27

669 DOI 10.1007/s11099-015-0140-3

670 Wang P, Sun X, Li C, Wei ZW, Liang D, Ma FW. 2013. Long-term exogenous application of

671 melatonin delays drought-induced leaf senescence in apple. Journal of Pineal Research 54(3):

672 292-302 DOI 10.1111/jpi.12017

673 Wang P, Yin LH, Liang D, Li C, Ma FW, Yue ZY. 2012. Delayed senescence of apple leaves

674 by exogenous melatonin treatment: toward regulating the ascorbate-glutathione cycle. Journal of

675 Pineal Research 53(1): 11-20 DOI 10.1111/j.1600-079X.2011.00966.x

676 Wang YB, Yao QQ, Zhang YS, Zhang YX, Xing JP, Yang BZ, Mi GH, Li ZH, Zhang MC.

677 2020. The role of gibberellins in regulation of nitrogen uptake and physiological traits in maize 
678 responding to nitrogen availability. International Journal of Molecular Sciences 21(5).1824 DOI 679 10.3390/ijms21051824

680 Xiao S, Liu LT, Wang H, Li DX, Bai ZY, Zhang YJ, Sun HC, Zhang K, Li CD. 2019.

681 Exogenous melatonin accelerates seed germination in cotton (Gossypium hirsutum L.). PLoS

682 ONE 14(6): e0216575 DOI 10.1371/journal.pone.0216575

683 Yang H, Dai LJ, Wei YX, Deng Z, Li DJ. 2020. Melatonin enhances salt stress tolerance in 684 rubber tree (Hevea brasiliensis) seedlings. Industrial Crops and Products 145(C) DOI 685 10.1016/j.indcrop.2019.111990

686 Yang YQ, Guo Y. 2018. Unraveling salt stress signaling in plants. Journal of Integrative Plant 687 Biology, 60(9): 796-804 DOI 10.1111/jipb.12689

688 Ye J, Wang SW, Deng XP, Yin L, Xiong BL, Wang XY. 2016. Melatonin increased maize 689 (Zea mays L.) seedling drought tolerance by alleviating drought-induced photosynthetic 690 inhibition and oxidative damage. Acta Physiologiae Plantarum 38(2): 48 DOI 10.1007/s11738691 015-2045-y

692 Yin ZP, Lu JZ, Meng SD, Mostafa I, Qi MF, Li TL. 2019. Exogenous melatonin improves 693 salt tolerance in tomato by regulating photosynthetic electron flux and the ascorbate-glutathione 694 cycle. Journal of Plant Interactions 14(1): 453-463 DOI 10.1080/17429145.2019.1645895

695 Zhan HS, Nie XJ, Zhang T, Li S, Wang XY, Du XH, Tong W, Song WN. 2019. Melatonin: a 696 small molecule but important for salt stress tolerance in plants. International Journal of 697 Molecular Sciences 20(3) DOI 10.3390/ijms20030709

698 Zhang HJ, Zhang N, Yang RC, Wang L, Sun QQ, Li DB, Cao YY, Weeda Sarah, Zhao B, 699 Ren SX, Guo YD. 2014. Melatonin promotes seed germination under high salinity by regulating 700 antioxidant systems, ABA and $\mathrm{GA}_{4}$ interaction in cucumber (Cucumis sativus L.). Journal of 701 Pineal Research 57(3):269-279 DOI 10.1111/jpi.12167

702 Zhang N, Sun QQ, Zhang HJ, Cao YY, Weeda S, Ren SX, Guo YD. 2015. Roles of 703 melatonin in abiotic stress resistance in plants, Journal of Experimental Botany, 66(3):647-56

704 DOI 10.1093/jxb/eru336

705 Zhang N, Zhao B, Zhang HJ, Weeda S, Yang C, Yang ZC, Ren SX, Guo YD. 2013.

706 Melatonin promotes water-stress tolerance, lateral root formation, and seed germination in 707 cucumber (Cucumis sativus L.). Journal of Pineal Research 54(1):15-23 DOI 10.1111/j.1600708 079X.2012.01015.X 
709 Zhang YP, Yang SJ, Chen YY. 2017. Effects of melatonin on photosynthetic performance and 710 antioxidants in melon during cold and recovery. Biologia Plantarum 61(3): 571-578 DOI

711 10.1007/s10535-017-0717-8

712 Zhao HL, Ye L, Wang YP, Zhou XT, Yang JW, Wang JW, Cao K, Zou ZR. 2016.

713 Melatonin increases the chilling tolerance of chloroplast in cucumber seedlings by regulating

714 photosynthetic electron flux and the ascorbate-glutathione cycle. Frontiers in Plant Science

715 1814-1814 DOI 10.3389/fpls.2016.01814 
Figure 1

Effects of exogenous melatonin (MT) on cotton seedling phenotype (A), plant height (B), and leaf area (C) of cotton seedlings. 

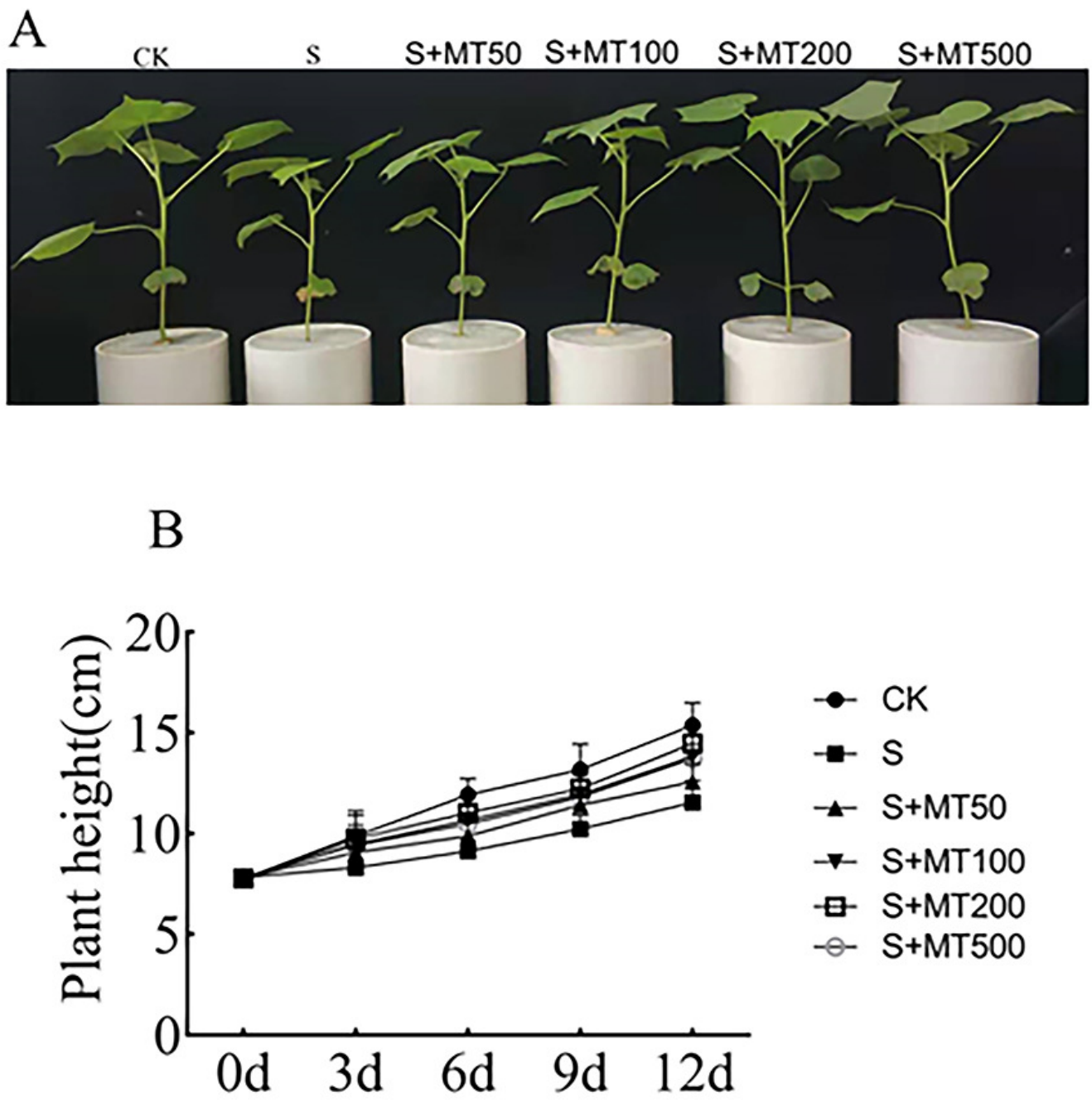

Days after treatment $/ \mathrm{d}$

C

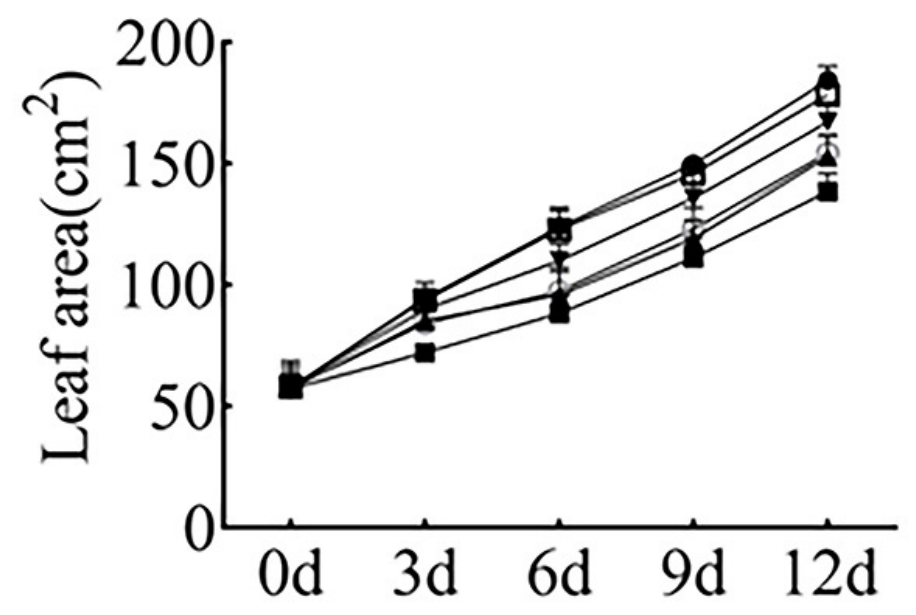

Days after treatment $/ \mathrm{d}$ 
Figure 2

Effects of exogenous melatonin (MT) on hydrogen peroxide $\left(\mathrm{H}_{2} \mathrm{O}_{2}\right)(A)$, superoxide anion $\left(\mathrm{O}_{2}{ }^{-}\right)(\mathrm{B})$, superoxide anion production rate $(\mathrm{C})$, and malondialdehyde (MDA) (D) content in cotton leaves under salt stres

Control (CK) and salt-treated (S) plants were sprayed with distilled water, while the $\mathrm{S}+$ MT50, S + MT100, S + MT200, and S + MT500 plants were sprayed with 50, 100, 200, 500 $\mu \mathrm{M}$ MT, respectively. Different lowercase letters indicate significant differences at a $P \leq 0.05$ threshold.

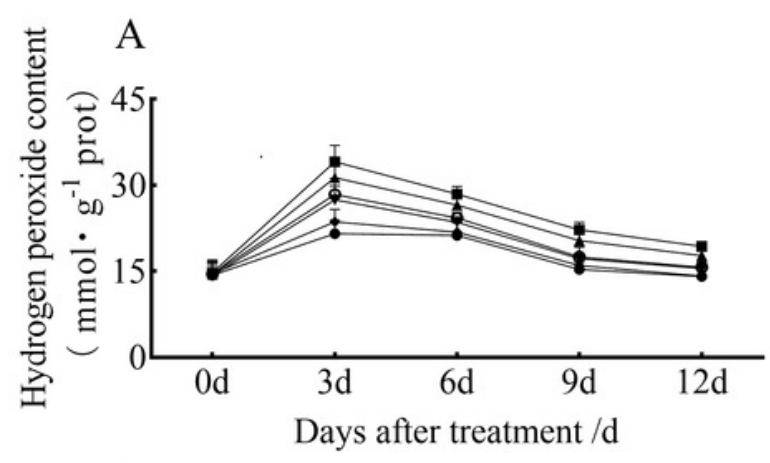

$\mathrm{C}$

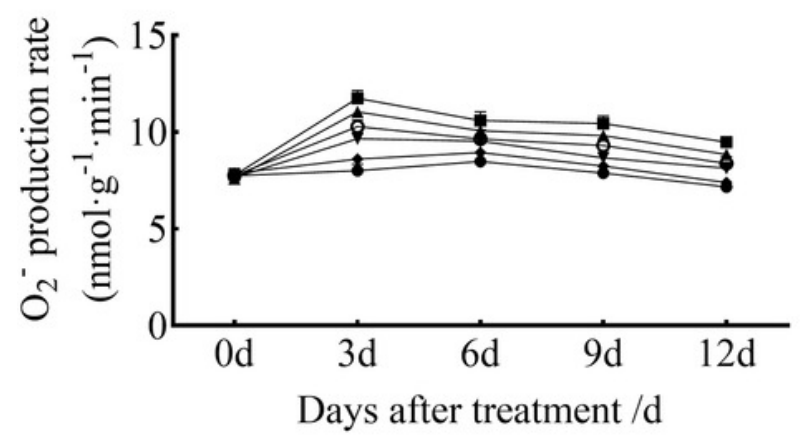

B
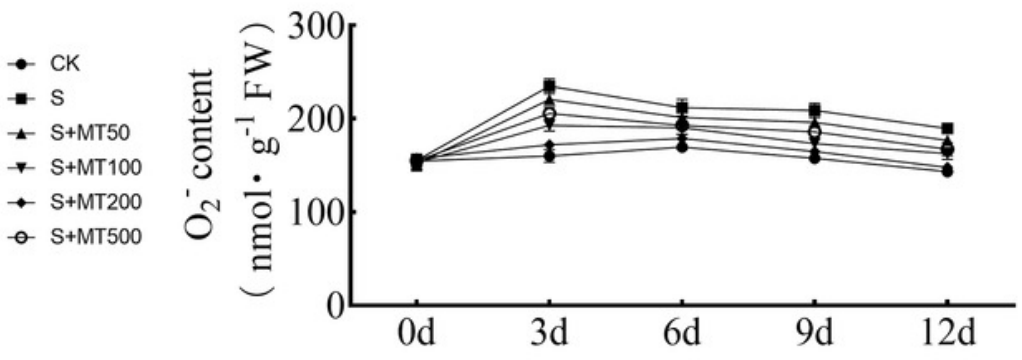

Days after treatment $/ \mathrm{d}$

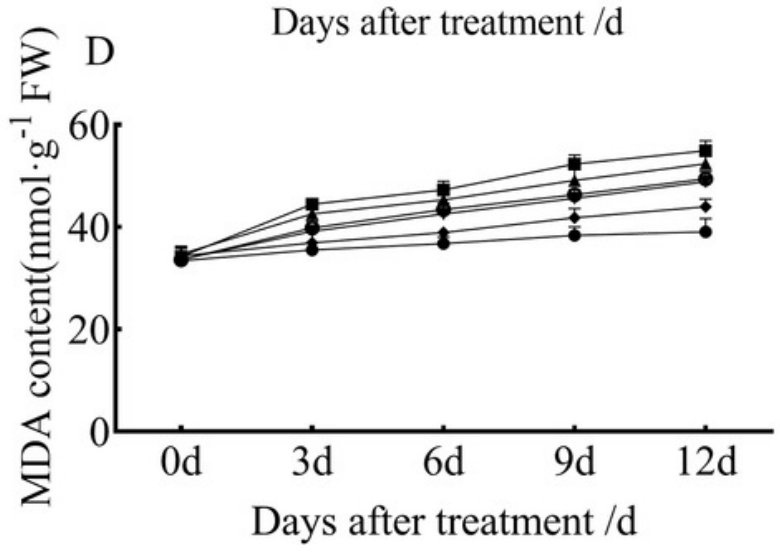




\section{Figure 3}

Effects of exogenous melatonin (MT) treatment on superoxide dismutase (SOD) (A), peroxidase (POD) (B), catalase (CAT) (C), and ascorbate peroxidase (APX) (D) activities of cotton leaves under salt stress.

Control (CK) and salt-treated (S) plants were sprayed with distilled water, while S + MT50, S + MT100, S + MT200, and S + MT500 plants were sprayed with 50, 100, 200, and $500 \mu \mathrm{M}$ MT, respectively. Different lowercase letters indicate significant differences at the $P \leq 0.05$ level.
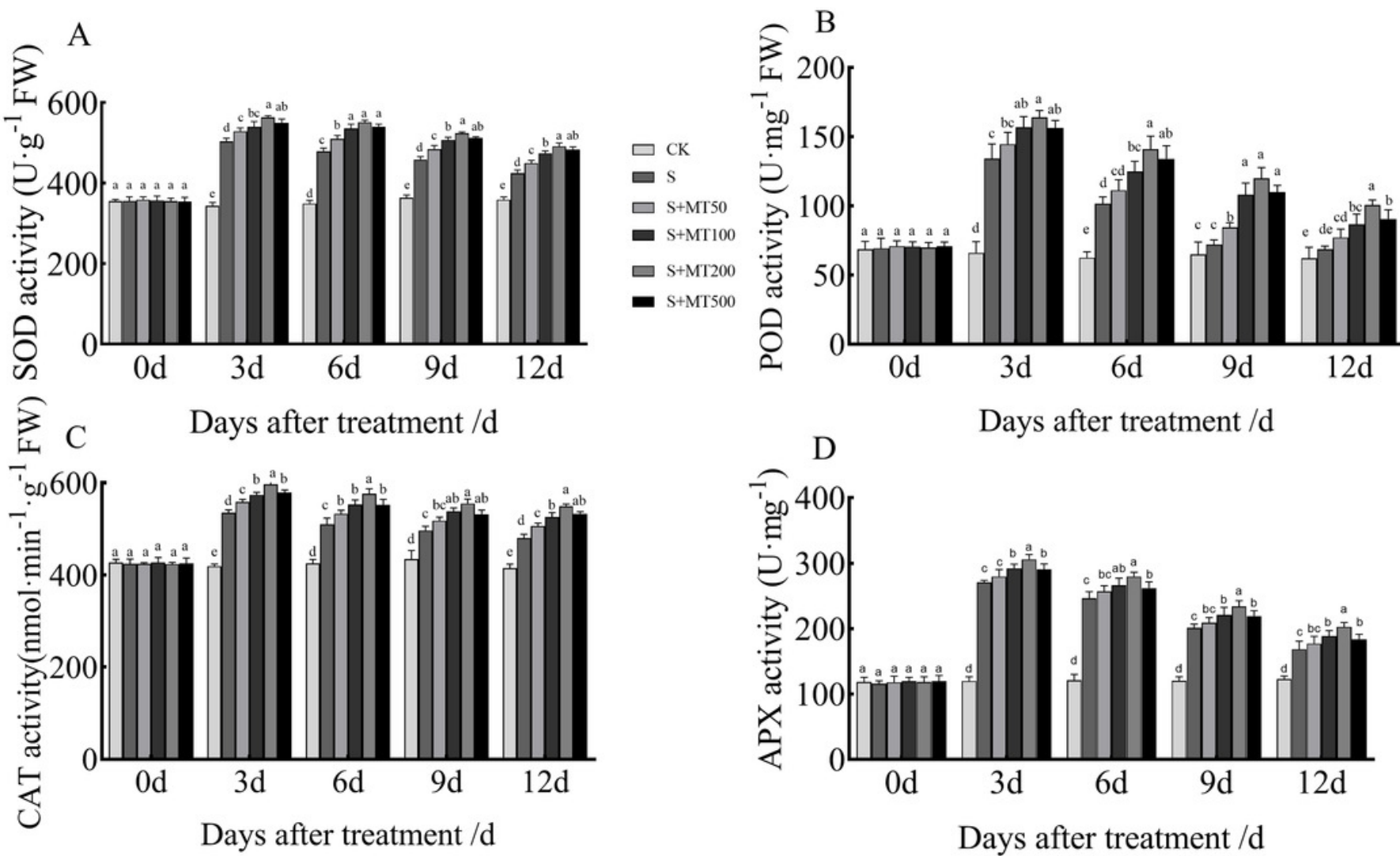


\section{Figure 4}

Effects of exogenous melatonin (MT) treatment on ascorbic acid (AsA) (A) and glutathione (GSH) (B) contents of cotton leaves under salt stress.

Control (CK) and salt-treated (S) plants were sprayed with distilled water, while S + MT50, S + MT100, S + MT200, and S + MT500 plants were sprayed with 50, 100, 200, and $500 \mu \mathrm{M}$ MT, respectively. Different lowercase letters indicate significant differences at a $P \leq 0.05$ threshold.

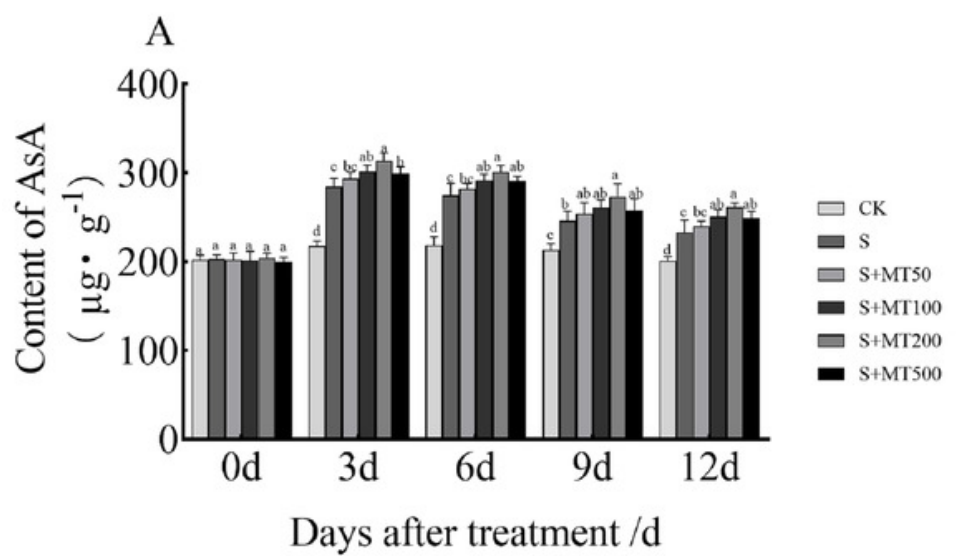

Days after treatment /d

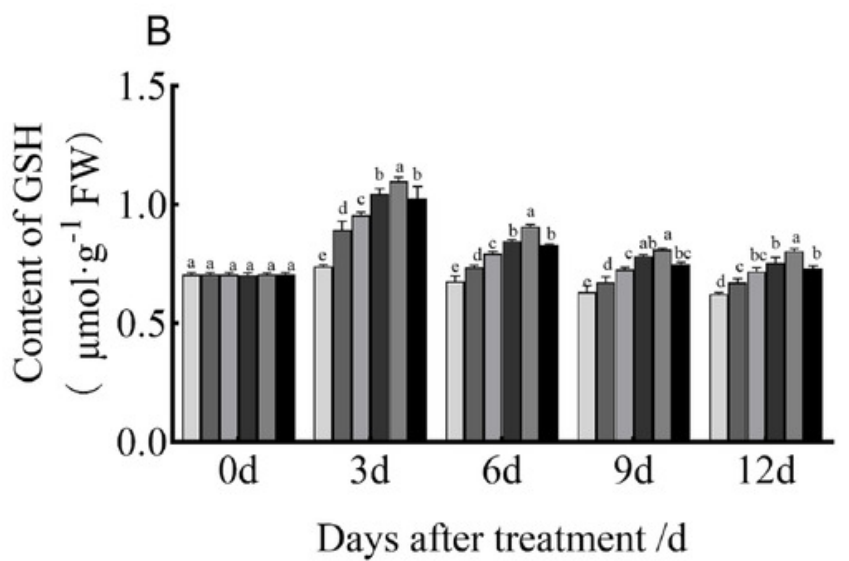


Figure 5

Effects of exogenous melatonin (MT) treatment on soluble sugar (A) and soluble protein (B) contents of cotton leaves under salt stress.

Control (CK) and salt-treated (S) plants were sprayed with distilled water, while S + MT50, S + MT100, S + MT200, and S + MT500 plants were sprayed with 50, 100, 200, and $500 \mu \mathrm{M}$ MT, respectively. Different lowercase letters indicate significant differences at a $P \leq 0.05$ threshold.
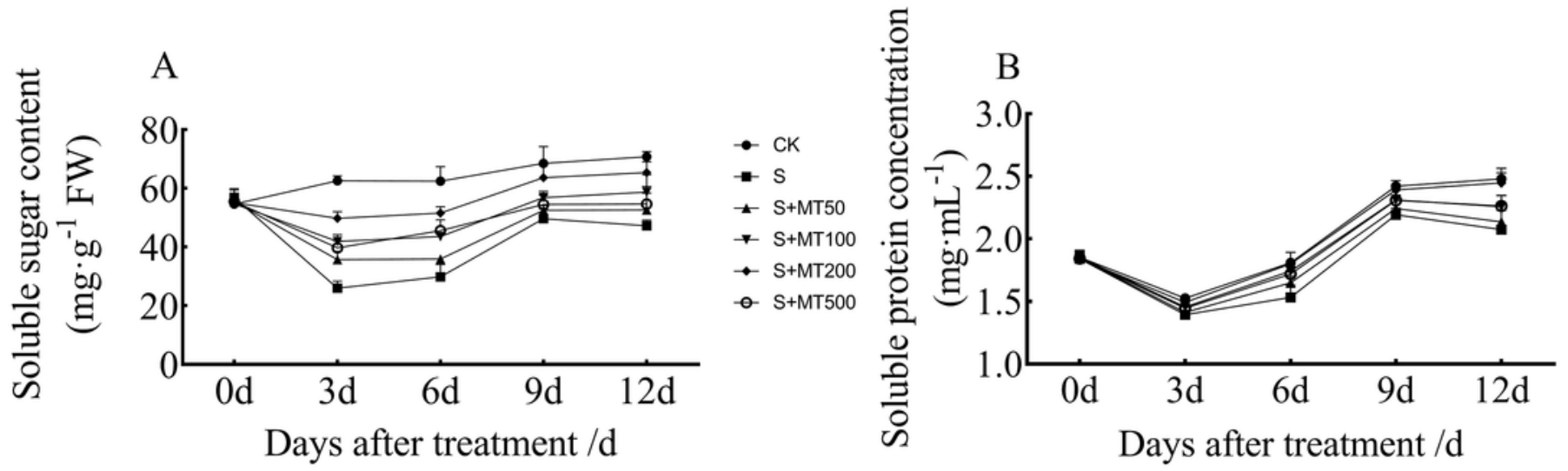